\title{
Carpogenic Germinability of Diverse Sclerotinia sclerotiorum Populations Within the Southwestern Australian Grain Belt
}

\author{
Pippa J. Michael, ${ }^{1, \dagger}$ King Yin Lui, ${ }^{1}$ Linda L. Thomson, ${ }^{1}$ Katia Stefanova, ${ }^{2}$ and Sarita J. Bennett ${ }^{1}$ \\ ${ }^{1}$ Centre for Crop and Disease Management, Curtin University, Bentley, WA 6845, Australia \\ ${ }^{2}$ SAGI-WEST, Curtin University, Bentley, WA 6845, Australia
}

\begin{abstract}
Sclerotinia stem rot, caused by the necrotrophic plant pathogen Sclerotinia sclerotiorum (Lib.) de Bary, is a major disease of canola and pulses in Australia. Current disease management relies greatly on cultural and chemical means of control. Timing of fungicide applications remains a challenge, because efficacy is dependent on accurate prediction of ascospore release and presence on the plant. The aims of this study were to determine the optimal temperature for carpogenic germination of S. sclerotiorum populations sampled from canola and lupin fields in southwestern Australia and characterize diversity using mycelial compatibility groupings (MCGs). Sclerotia were collected from four diseased canola and one diseased lupin field from across southwestern Australia. Forty sclerotia from each population

using 12 reference isolates. Results indicated the time to initial carpogenic germination decreased as diurnal temperature fluctuations decreased, with a fluctuation of $5^{\circ} \mathrm{C}\left(20 / 15^{\circ} \mathrm{C}\right)$ having the most rapid initial germination followed by $11^{\circ} \mathrm{C}\left(15 / 4^{\circ} \mathrm{C}\right)$ followed by $16^{\circ} \mathrm{C}\left(20 / 4^{\circ} \mathrm{C}\right)$. Optimal germination temperature for all five populations was $20 / 15^{\circ} \mathrm{C}$; however, population responses to other diurnal temperature regimes varied considerably. No germination was observed at $30 / 15^{\circ} \mathrm{C}$. MCG results indicate extensive diversity within and between populations, with at least $40 \%$ of sclerotia within each population unable to be characterized. We suggest that this diversity has enabled S. sclerotiorum populations to adapt to varying environmental conditions within southwestern Australia.
\end{abstract} were incubated at four alternating temperatures of 30/15, 20/15, 20/4, and $15 / 4^{\circ} \mathrm{C}(12-\mathrm{h} / 12$-h light/dark cycle) and assessed every 2 to 3 days for a 180-day period. MCG groupings for populations were characterized
Keywords: Sclerotinia stem rot, apothecia, germination, disease management, mycelial compatibility grouping, MCG
Sclerotinia sclerotiorum (Lib.) de Bary is a necrotrophic plant pathogen with an extensive host range, with the potential to infect over 400 plant species across 75 families (Boland and Hall 1994). The fungus damages plant tissue leading to cell death and appears as a soft rot or white mold (Purdy 1956). S. sclerotiorum can cause extensive financial losses through reduced yield and seed quality of important dicotyledonous crops such as canola/rapeseed (Brassica napus L.), peanut (Arachis hypogaea L.), soybean (Glycine max L. Merr.), and sunflower (Helianthus annuus L.), as well as monocotyledonous crops such as onion (Allium cepa L.) and tulip (Tulipa spp.) (Boland and Hall 1994; Bolton et al. 2006). In Australia, S. sclerotiorum infections can lead to major outbreaks of Sclerotinia stem rot (SSR) disease in canola and pulse crops (i.e., lupin, Lupinus angustifolius L.). Under SSR-favorable conditions and unmanaged in canola, this disease could potentially cost the agricultural industry over AUD\$40 million annually (Murray and Brennan 2012).

Management of SSR in Australia relies heavily on cultural and chemical means of control, with no canola cultivars with complete SSR resistance currently available (Kamal et al. 2016). Current cultural practices aim to reduce inoculum levels in the soil or create environments unsuitable for disease development. These are under pressure as crop rotations narrow and inoculum levels rise (Derbyshire and Denton-Giles 2016) due to an escalation of canola plantings in Australia (Brooks et al. 2018) and long-term persistence of inoculum in the soil (up to 8 years) (Bolton et al. 2006). Furthermore, although a limited number of fungicides have been registered for SSR

${ }^{\dagger}$ Corresponding author: P. J. Michael; p.michael@curtin.edu.au

Funding: This work was supported by Grains Research and Development Corporation (GRDC) grant number CUR00023.

The author(s) declare no conflict of interest.

Accepted for publication 6 May 2020.

(c) 2020 The American Phytopathological Society in Australia (Kamal et al. 2016), the timing of foliar fungicide spraying to minimize yield losses and avoid unnecessary applications is challenging, because efficacy is dependent on accurately predicting when fungal ascospores are released and present on floral tissue (Derbyshire and Denton-Giles 2016). Even if foliar fungicides are applied at the optimum timing of infection, the development of SSR requires specific environmental conditions to be met. Thus, an understanding of the conditions necessary for SSR inoculum production, infection, and disease development are vital to optimum disease management (Clarkson et al. 2014).

S. sclerotiorum produces hard asexual inoculum called sclerotia, melanized hyphal aggregates that lie dormant in and on the soil and that are the primary long-term survival structures of the fungus (Bolton et al. 2006). Depending on environmental conditions, sclerotia can germinate either carpogenically, producing airborne ascospores from apothecia and infecting above-ground parts of plant hosts, or myceliogenically, producing hyphae that directly infect the stem or roots (Bolton et al. 2006). The majority of disease epidemics caused by $S$. sclerotiorum are a result of infection by ascospores that may potentially be dispersed over several kilometers via air currents (Li et al. 1994) but are typically disseminated within 40 to $60 \mathrm{~m}$ of their apothecial origin (Qandah and Del Rio Mendoza 2012). Although it is well known that soil moisture is crucial for the production of apothecia, with ascospore-initiated diseases directly linked to periods of high rainfall or irrigation (Bolton et al. 2006), other conditioning factors, such as sclerotial germination temperature, are often inconsistent. Optimal constant temperatures vary considerably with reports of 11 to $15^{\circ} \mathrm{C}$ (Abawi and Grogan 1979), 10 to $20^{\circ} \mathrm{C}$ (Phillips 1986; Wu and Subbarao 2008), 15 to $20^{\circ} \mathrm{C}$ (Clarkson et al. 2004), and 18 to $20^{\circ} \mathrm{C}$ (Sun and Yang 2000). Additionally, no apothecia formed at temperatures of 30 or $5^{\circ} \mathrm{C}$ (Abawi and Grogan 1979), $25^{\circ} \mathrm{C}$ (Wu and Subbarao 2008), and 26 or $29^{\circ} \mathrm{C}$ (Clarkson et al. 2004)

This variation in the literature may be due to the narrow diversity of isolates typically examined, in which only a small number of isolates or locations are used, and they are generally recultured under controlled temperature environments (Clarkson et al. 2004; Foley et al. 2016; Purdy 1956; Wu and Subbarao 2008). Collection of 
multiple sclerotia from several locations within the field eliminates the requirement for bulking sclerotia under controlled environments, and it provides a representative subsample of population isolates. In this manner, the response to germination temperature can be directly related to environmental conditions at the location where sclerotia were formed. Furthermore little is understood about the impact of fluctuating temperatures on germination, although a study by Mila and Yang (2008) found that fluctuating temperatures of $16 / 24^{\circ} \mathrm{C}$ (12-h/12-h light/dark) produced much higher and more rapid carpogenic germination of isolates from a single field in Iowa than those incubated at $18 / 22^{\circ} \mathrm{C}, 14 / 26^{\circ} \mathrm{C}$, and a constant $20^{\circ} \mathrm{C}$.

S. sclerotiorum is primarily homothallic (having male and female reproductive structures on the same thallus) and produces ascospores after self-fertilization without creating any asexual spores (Kamal et al. 2016). This results in a predominately clonal population structure composed of a small number of clones at high frequencies, with the remainder found only once or a few times (Clarkson et al. 2013; Kohli et al. 1995). In contrast, there are reports of outcrossing and exchange of genotypes in S. sclerotiorum populations (Attanayake et al. 2014; Derbyshire et al. 2019; Malvárez et al. 2007), potentially increasing the genetic diversity and adaptability of the pathogen. One way of characterizing diversity in populations of S. sclerotiorum is by using mycelial compatibility groupings (MCGs), a phenotypic marker controlled by multiple loci and based on the ability of two isolates to form one indistinct colony. This method of characterization is often closely associated with DNA fingerprints or microsatellite alleles (Aldrich-Wolfe et al. 2015; Clarkson et al. 2013; Liu et al. 2018; Schafer and Kohn 2006; Sexton et al. 2006). Correlations between phenotypic and genetic diversity have been determined for various agronomic traits including aggressiveness (Denton-Giles et al. 2018; Garg et al. 2010b; Kohli et al. 1995; Leyronas et al. 2018), fungicide sensitivity, and sclerotia production (Attanayake et al. 2013). In contrast, several studies found no correlation between genetic diversity and phenotypic traits such as aggressiveness (Durman et al. 2003; Sexton and Howlett 2004) and crop host type (Aldrich-Wolfe et al. 2015; Clarkson et al. 2013; Leyronas et al. 2018). Understanding phenotypic and genetic diversity of agronomically important traits of a pathogen is important in the development of disease management strategies.

The objective of this study was to determine the optimal temperature for carpogenic germination of five geographically distinct populations of S. sclerotiorum sampled from canola and lupin fields in southwestern Australia. Populations were characterized using MCGs, with results related back to location and host species.

\section{Materials and Methods}

Field sampling of sclerotes. Sclerotia of S. sclerotiorum were collected from diseased canola (B. napus) and lupin (L. angustifolius) crop plants within the southwestern Australian grain belt (Fig. 1). Sclerotia from four populations (Bentley, Beverley, Darkan, and Mingenew [canola]) were collected from a minimum of 12 infected canola stems during spring 2016, whereas sclerotia from the remaining population, Mingenew (lupin), were sampled in April 2017 from lupin seed grown the previous season (2016). All sclerotia were collected from commercial fields with the exception of the Bentley population, which was sourced from canola plants inoculated with a known isolate, CU8.30 (Denton-Giles et al. 2018), and grown under field conditions. Sclerotia were stored in paper bags at room temperature $\left(\sim 20^{\circ} \mathrm{C}\right)$ in the laboratory at Curtin University $\left(-32.00581^{\circ}\right.$, $115.89662^{\circ}$ ) until commencement of the experiment. Monthly rainfall data and average minimum and maximum monthly soil temperature $\left({ }^{\circ} \mathrm{C}\right)$ data were sourced from the nearest $(<12 \mathrm{~km})$ Department of Primary Industries and Regional Development weather station for each location (Fig. 2).

Effect of temperature on carpogenic germination. On 11 October 2017 , four replicates of 10 sclerotia from each of the five populations were placed on 500-ml trays containing a sterilized vermiculite and washed sand mixture (1:1 sand/vermiculite by volume) and incubated in growth cabinets (Conviron) set at four alternating temperatures of $30 / 15,20 / 15,20 / 4$, and $15 / 4^{\circ} \mathrm{C}(12-\mathrm{h} / 12-\mathrm{h}$ light/dark cycle). The vermiculite/sand mixture was initially autoclaved before adding reverse osmosis (RO) water until the mixture reached water-holding capacity. Approximately $250 \mathrm{ml}$ of moist vermiculite/sand mixture was aliquoted into 500-ml rectangular plastic food-grade trays and the surface leveled and smoothed before placing the 10 sclerotia on the surface. Trays were covered with a plastic lid and regularly sprayed with RO water to keep sclerotes moist. A total of 80 trays (5 populations $\times 4$ temperatures $\times 4$ replicates) containing 10 sclerotia each were established (800 sclerotia in total, 160 per population). Time (days) to emergence of stipes and apothecia was assessed at regular intervals over a 180-day period (100 assessments in total).

MCGs. Following completion of the germination study, 40 sclerotia were randomly selected from Beverley, Darkan, and both Mingenew populations (160 sclerotia in total) to obtain fungal cultures. The Bentley population was not tested for MCGs because it was inoculated from a pure isolate (CU8.30). Each sclerotium was surface sterilized in bleach (White King premium bleach; $4 \% \mathrm{v} / \mathrm{v}$ sodium hypochlorite) for $4 \mathrm{~min}$ followed by $4 \mathrm{~min}$ in $4 \%$ ethanol and then a final wash in sterile Milli-Q water for $4 \mathrm{~min}$. Sclerotia were cut in half and placed in 90-mm Petri dishes containing half-strength potato dextrose agar (PDA) supplemented with neomycin $(50 \mu \mathrm{g} / \mathrm{ml})$, streptomycin $(100 \mu \mathrm{g} / \mathrm{ml})$, and ampicillin $(100 \mu \mathrm{g} / \mathrm{ml})$ and incubated at room temperature $\left(\sim 20^{\circ} \mathrm{C}\right)$ in the dark until actively growing mycelium was visible (3 to 5 days). Each isolate was subcultured twice onto PDA by extracting an agar plug from the margins of mycelial growth. After approximately 2 weeks, sclerotia were fully formed, and the culture was left to dry out completely before sclerotia were extracted and stored in 2-ml microcentrifuge tubes at $4^{\circ} \mathrm{C}$ until required.

Mycelial cultures were grown from stored sclerotia as detailed previously and incubated at $20^{\circ} \mathrm{C}$ in the dark for 4 days. Isolates were tested against 12 reference MCG isolates previously characterized by Denton-Giles et al. (2018) from 71 isolates collected from across the southwestern Australian grain belt in 2013 and 2014 (Table 1). An agar plug was taken from actively growing mycelium of the uncategorized isolate and transferred to the center of a 90-mm Petri dish containing PDA supplemented with $100 \mu \mathrm{l} / \mathrm{ml}$ of Queen's red food coloring. A maximum of six reference MCG isolates were arranged evenly around the center test isolate, spacing reference isolates approximately equal distance from the center test isolate and from each neighboring reference isolate. Mycelial compatibility was assessed at

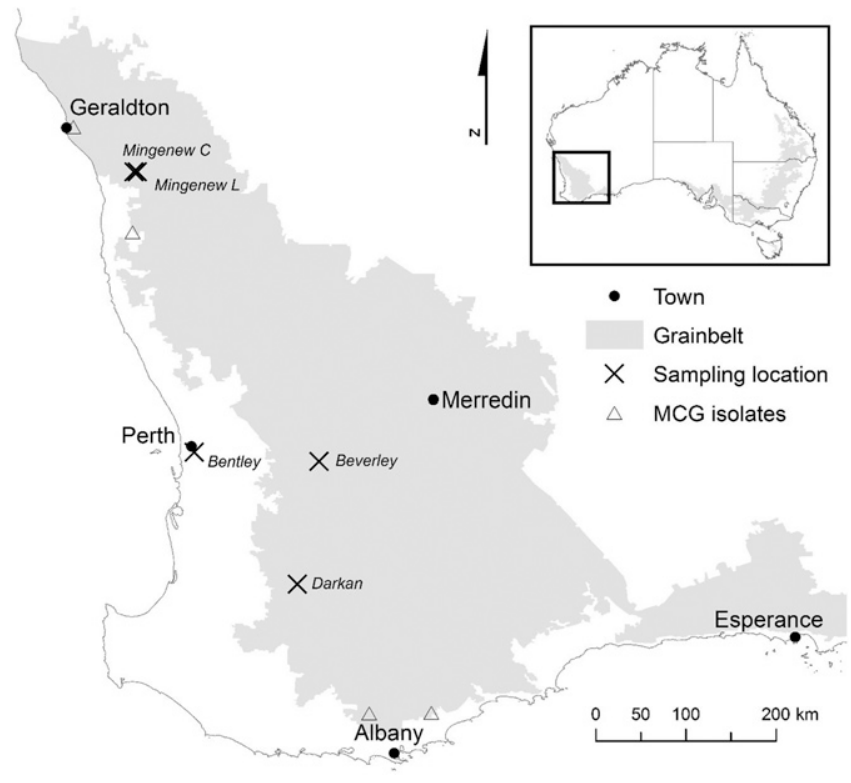

Fig. 1. Map illustrating locations of the five Sclerotinia sclerotiorum populations collected within the southwestern Australian grain belt. Mycelial compatibility grouping (MCG) isolate locations collected by Denton-Giles et al. (2018) are also shown. 
$72 \mathrm{~h}$ with a red dye barrier between mycelium indicating an incompatible interaction and merged mycelium indicating compatibility as described in Denton-Giles et al. (2018). The experiment was then repeated to confirm results.

Statistical analysis and geographic information system methods. A nonlinear regression was used to model the dynamic of carpogenic germination in time. Germination data were analyzed in $\mathrm{R}$ version 3.5.1 (R Core Team 2018) using the drc package (Ritz et al. 2015). A binomial distribution was assumed, and a nonlinear regression analysis was applied. Sclerotia germination proportions were fitted to a standard three-parameter log-logistic distribution function:

$$
F(t)=\frac{d}{1+\exp \left[b\left(\log (t)-\log \left(\mathrm{t}_{50}\right)\right)\right]}
$$

where $F$ is sclerotia germination (\%) in response to time $t, d$ denotes the upper limit of the sigmoid-shaped asymptotic curve, and $b$ is the relative slope at $t_{50}$, where $50 \%$ of all sclerotia germinated during the experiment have germinated. This statistical model is regularly used in biology, toxicology, and weed science including for dose-response models and other linear and nonlinear regression models (Ritz et al. 2015). To test for statistical differences between the curve parameters we used the compParm function in the drc package $(P<0.05)$.

A generalized linear mixed model (GLMM) analysis was used to analyze final carpogenic germination in Genstat version 18 (VSN International 2019), using the GLMM procedure. Data were presented as proportions and analyzed assuming binomial error distribution with the logit link function. Blocking structure was accounted for in the model and fitted as random. The treatment structure was fitted as fixed and consisted of the main effects of temperature and population and their interaction. Means and standard errors were visually presented on the original data scale to enable meaningful elucidation of results. Means were separated by Tukey's honestly significant difference (HSD; $P<0.05$ ).

Data were plotted using SigmaPlot version 13 (Systat Software, San Jose, CA) and maps generated with ArcMap version 10.4 (Esri, Redlands, CA).

\section{Results}

Log-logistic models. Days to first carpogenic germination was most rapid for populations incubated at $20 / 15^{\circ} \mathrm{C}$, occurring after 42 to 45 days of incubation (Fig. 3). This was followed by populations incubated at $15 / 4^{\circ} \mathrm{C}$ ( 48 to 61 days) and $20 / 4{ }^{\circ} \mathrm{C}$ (60 to 68 days). No germination was observed at $30 / 15^{\circ} \mathrm{C}$. Incubation temperature had a significant effect $(P<0.01)$ on average days to first germination; however, population source did not.

The three-parameter log-logistic model of the cumulative germination proportions produced a good fit $(P<0.01)$ for all parameters (Fig. 3). The exception was parameter $b$, which was not significant in the Darkan population at $20 / 4^{\circ} \mathrm{C}$. Analysis of parameters extrapolated from the models (Table 2) showed the rate of germination at $t_{50}$ (parameter $b$ ) was similar when grouped by both population and temperature, with the exception of Bentley, which had a significantly faster rate at $15 / 4^{\circ} \mathrm{C}$ compared with $20 / 15^{\circ} \mathrm{C}(P<0.05)$ at $t_{50}$ (time to reach $50 \%$ germination). For parameter $d$ (upper asymptotic value of $Y$ ), there were substantial differences $(P<0.05)$ between

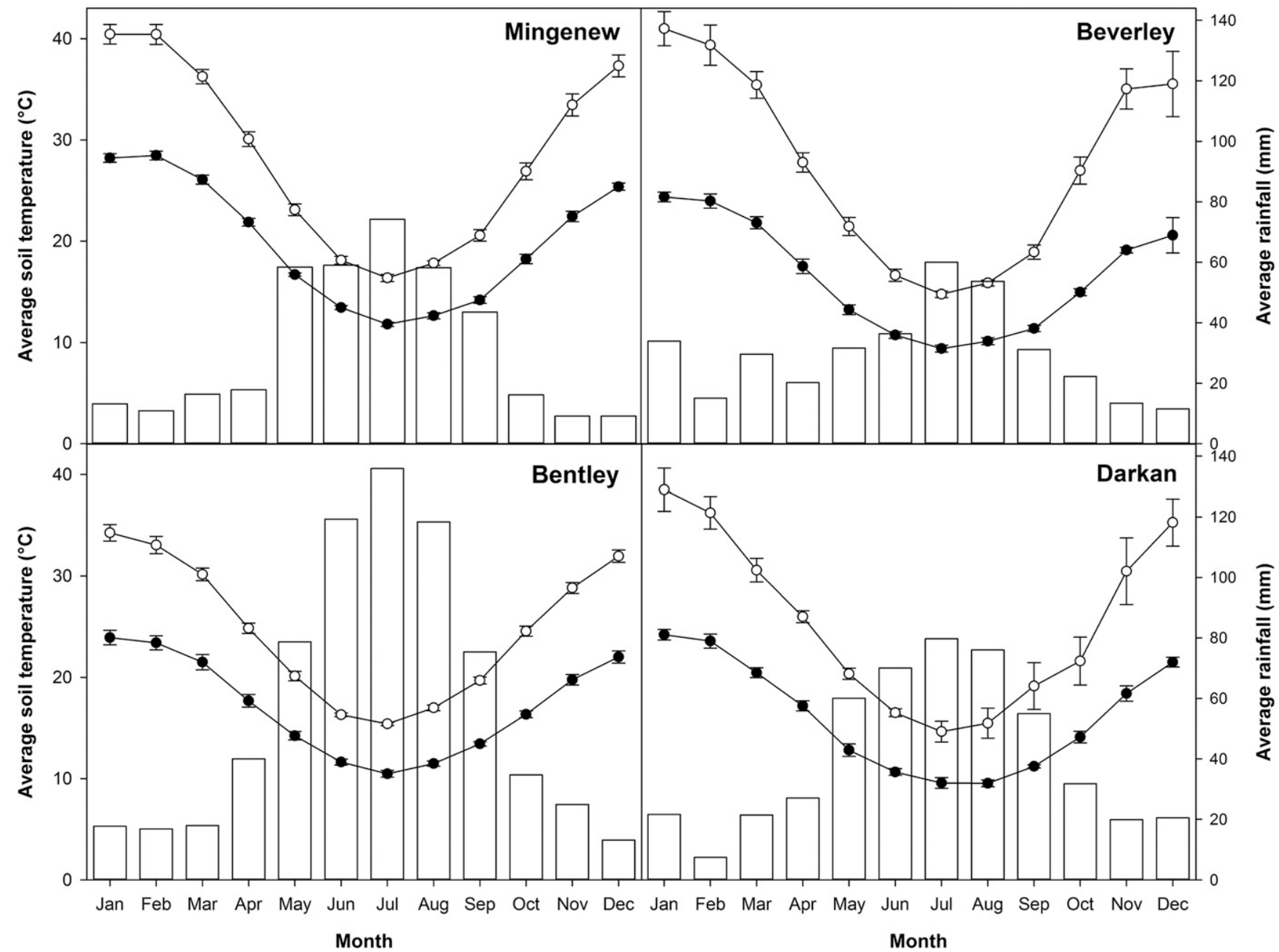

Fig. 2. Monthly average minimum $(\bullet)$ and maximum $(\bigcirc)$ soil temperature $( \pm S E)$ and rainfall $(\square)$ for each location. Monthly rainfall data and average minimum and maximum monthly soil temperature $\left({ }^{\circ} \mathrm{C}\right)$ data were sourced from the nearest Department of Primary Industries and Regional Development weather station. 
populations when incubated at $15 / 4^{\circ} \mathrm{C}$, with the upper asymptotic value being significantly greater in Mingenew (lupin) and Beverley compared with Darkan, Bentley, and Mingenew (canola). When incubated at $20 / 4^{\circ} \mathrm{C}$, Darkan had a lower $d$-parameter value $(P<0.001)$ than the other four populations. There was also a significant difference between Beverley and Mingenew (canola) $(P<0.05)$, which had a lower asymptotic value compared with Mingenew (lupin) and Bentley. Only the two Mingenew populations had a marked difference between the $d$ parameter when incubated at $20 / 15^{\circ} \mathrm{C}$.

Final germination. The GLMM indicated that temperature and population both had a significant effect $(P<0.001)$ on final carpogenic germination $\left(d_{180}\right)$ (Fig. 4$)$. A higher frequency of sclerotia germinated when incubated at $20 / 15^{\circ} \mathrm{C}(84 \pm 3.6 \%)$ than at $15 / 4{ }^{\circ} \mathrm{C}$ $(70 \pm 4.6 \%)$ or $20 / 4^{\circ} \mathrm{C}(59 \pm 5.5 \%)$, with significant differences observed between each population (Tukey's HSD, $P<0.05$ ). Total germination was significantly higher $(P<0.05)$ in sclerotia sourced from Mingenew (lupin) $(84 \pm 3.4 \%)$, Bentley $(81 \pm 5.8 \%)$, and Beverley $(79 \pm 5.0 \%)$ compared with those from Mingenew (canola) $(60 \pm$ $3.9 \%)$ and Darkan $(52 \pm 8.4 \%)$ across all temperature variations excluding $30 / 15^{\circ} \mathrm{C}$, because no germination was observed at this treatment level.

A significant $(P<0.001)$ interaction between population and temperature was observed. Darkan sclerotia incubated at $20 / 4^{\circ} \mathrm{C}$ had a significantly lower germination percentage $(P<0.05)$ than all other populations (Fig. 4). All populations produced the highest total germination proportion when incubated at $20 / 15^{\circ} \mathrm{C}$, although the Mingenew (lupin) population total germination was equal to germination at the $15 / 4^{\circ} \mathrm{C}$ treatment. The second highest germination was recorded at $15 / 4^{\circ} \mathrm{C}$ for Beverley and Darkan and $20 / 4^{\circ} \mathrm{C}$ for Bentley and Mingenew (canola).

MCGs. Beverly isolates had the highest overall match (74\%) to the 12 reference isolates (Fig. 5) and were composed of three MCG groups. Darkan isolates matched to five MCGs (62\%), Mingenew (lupin) to eight MCGs (39\%), and Mingenew (canola) to four MCGs (26\%). Only MCG reference isolate IX was found in all four populations ( 8 to $26 \%$ of isolates), and reference isolates III and VI did not match any isolates in this study. Two Mingenew (lupin) isolates matched equally to two MCG reference isolates, with one matched to MCGs IV and X (3\%) and the other to both IV and XI $(3 \%)$. For all four populations, more than a quarter of all tested isolates did not match with any of the $12 \mathrm{MCG}$ reference isolates and were unknown (Fig. 5), ranging from $74 \%$ of all Mingenew (canola) isolates to $26 \%$ of the total Beverley isolates.

\section{Discussion}

The present investigation demonstrated significant differences in the carpogenic germinability of $S$. sclerotiorum populations from distinct agroecological zones and host plants under different

Table 1. Sclerotinia sclerotiorum reference isolates used in mycelial compatibility grouping (MCG) assays. All isolates sourced from Denton-Giles et al. (2018).

\begin{tabular}{lcllc}
\hline Isolate name & MCG & Original host & $\begin{array}{c}\text { Collection } \\
\text { locationa }^{\mathbf{a}}\end{array}$ & Year collected \\
\hline CU4.2 & I & Brassicanapus & Mount Barker, WA & 2014 \\
CU6.1 & II & B. napus & Mount Barker, WA & 2014 \\
CU8.20 & III & B. napus & South Stirling, WA & 2014 \\
CU8.24 & IV & B. napus & South Stirling, WA & 2014 \\
CU10.7 & V & B. napus & Geraldton, WA & 2014 \\
CU10.12 & VI & B. napus & Geraldton, WA & 2014 \\
CU10.17 & VII & B. napus & Geraldton, WA & 2014 \\
CU10.20 & VIII & B. napus & Geraldton, WA & 2014 \\
CU11.4 & IX & Lupinus albus & Eneabba, WA & 2013 \\
CU11.7 & X & L. albus & Eneabba, WA & 2013 \\
CU11.19 & XI & L. albus & Geraldton, WA & 2014 \\
CU8.30 & XII & B. napus & South Stirling, WA & 2014 \\
\hline
\end{tabular}

a WA = Western Australia.

${ }^{\mathrm{b}}$ MCG grouping XII was also characterized by Denton-Giles et al. (2018) but not published. temperature regimes. Optimal germination temperature for all five populations was $20 / 15^{\circ} \mathrm{C}(12-\mathrm{h} / 12$-h light/dark); however, population response to the other diurnal temperature regimes tested varied considerably. This is the first study to examine temperature requirements for carpogenic germination in ecological populations of $S$. sclerotiorum in Australia. Previous studies on the carpogenic germinability of $S$. sclerotiorum are limited, because they are primarily based on single recultured isolates sourced from distinct geographic origins and are not representative of an ecological population within a particular site (Clarkson et al. 2014, 2004, 2007; Dillard et al. 1995; Foley et al. 2016; Garg et al. 2010a; Huang and Kozub 1991, 1993). $\mathrm{Wu}$ and Subbarao (2008) examined nearly 100 recultured isolates from three different regions in California and found distinct differences in carpogenic germination when grouped by their location and MCG type. Their study only assessed germination at one constant temperature $\left(18^{\circ} \mathrm{C}\right)$ and was not related back to temperature at the source of origin. Recent studies that investigated carpogenic germination responses of ecological populations in relation to temperature have only examined a single population from one field (Mila and Yang 2008; Sun and Yang 2000). In contrast, our study examined sclerotia from within five distinct ecological populations collected from infected fields across a distance of $550 \mathrm{~km}$.

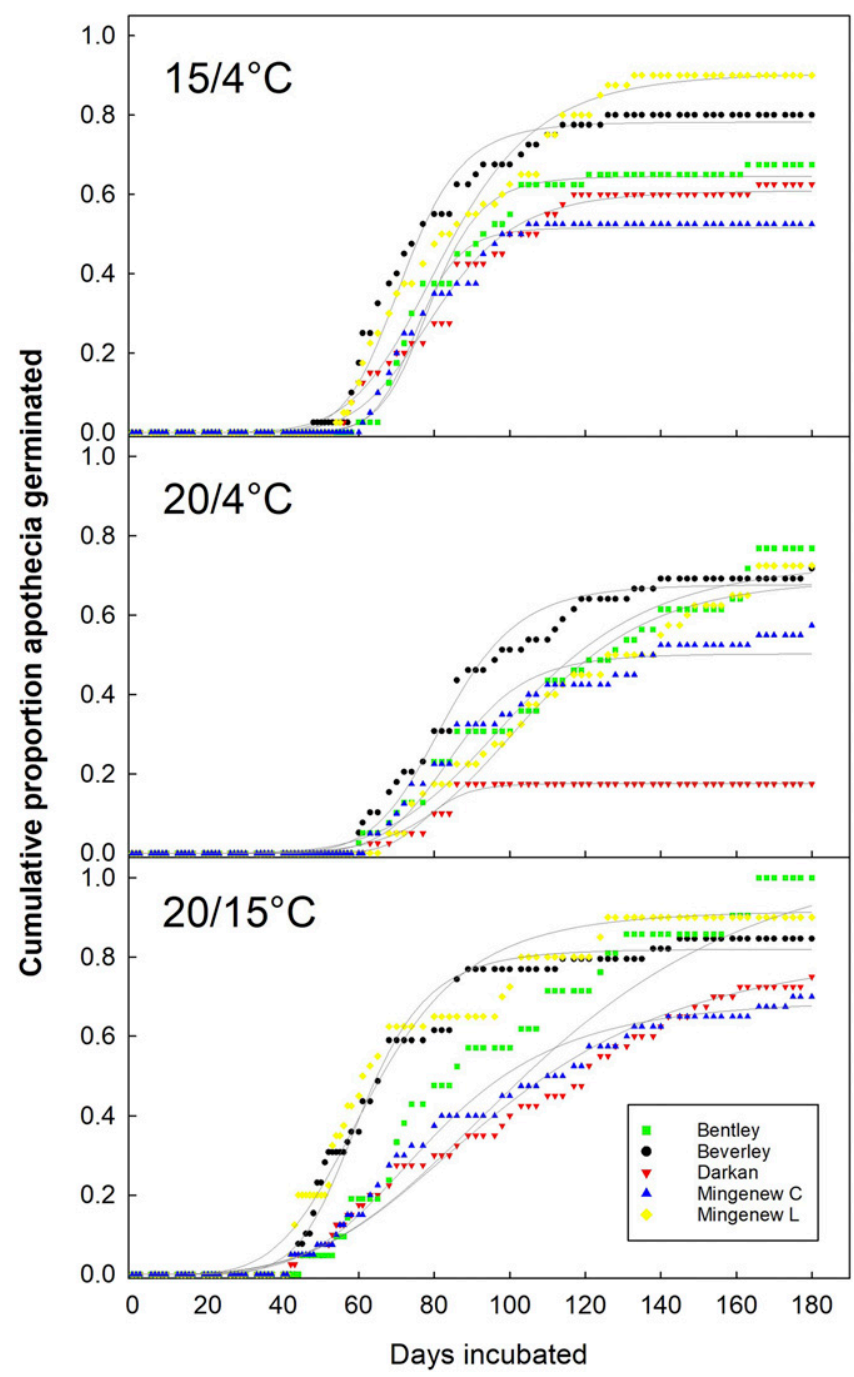

Fig. 3. Log-logistic model showing cumulative carpogenic germination of five Sclerotinia sclerotiorum populations, Bentley $(\square)$, Beverley $(\bigcirc)$, Darkan $(\boldsymbol{\nabla})$, Mingenew $C$ (canola) $(\triangle)$, and Mingenew $L$ (lupin) $(\bullet)$, incubated at four alternating temperatures $\left(15 / 4,20 / 15,20 / 4,30 / 15^{\circ} \mathrm{C} ; 12\right.$-h/12-h light/dark) and recorded every 1 to 3 days for 180 days (100 assessments) $\left(30 / 15^{\circ} \mathrm{C}\right.$ not shown because no germination was observed). 
Optimal temperature for carpogenic germination for all five populations in the present study occurred at a diurnal fluctuation of 20/ $15^{\circ} \mathrm{C}$ (12-h/12-h light/dark), a range consistent with published literature, in which temperatures were reported between 10 and $20^{\circ} \mathrm{C}$ (Abawi and Grogan 1979; Clarkson et al. 2004; Phillips 1986; Sun and Yang 2000; Wu and Subbarao 2008). However, these studies only investigated constant temperatures, with the exception of Mila and Yang (2008), who found in a comparison of a constant $20^{\circ} \mathrm{C}$ and four diurnal temperature ranges with averages of $20^{\circ} \mathrm{C}$ that the highest total carpogenic germination occurred at a diurnal temperature of $24 / 16^{\circ} \mathrm{C}$. All other diurnal temperatures were not significantly different to the constant $20^{\circ} \mathrm{C}$. This suggests that under field conditions sclerotia are sensitive to temperature cues, which are dependent on the location of origin. Within the mediterranean-type environment of southwestern Australia, optimal seed germination of many native plant species corresponds with temperatures between 13 and $20^{\circ} \mathrm{C}$ that coincide with the annual period of reliable winter rainfall (Bell 1999). We suggest a similar response occurs in S. sclerotiorum, which has adapted to the growing conditions in southwestern Australia. Garg et al. (2010a) provide support for our finding, because their study observed that the majority of sclerotia from two isolates sourced from within the southwest of Western Australia germinated during June to September, the period concurrent with reliable rainfall. Carpogenic germination did not occur at $30 / 15^{\circ} \mathrm{C}$ for any of the populations in this study, which correlated with published literature in which no germination was observed at constant temperatures of $25^{\circ} \mathrm{C}$ and above (Abawi and Grogan 1979; Clarkson et al. 2004; Wu and Subbarao 2008). This also agrees with the theory suggested above, because the temperature does not coincide with the annual rainfall period.

Time to initial carpogenic germination also decreased as diurnal temperature fluctuations decreased, with a fluctuation of $5^{\circ} \mathrm{C}(20 /$ $15^{\circ} \mathrm{C}$ ) having the most rapid initial germination, followed by $11^{\circ} \mathrm{C}$ $\left(15 / 4^{\circ} \mathrm{C}\right)$ and then $16^{\circ} \mathrm{C}\left(20 / 4^{\circ} \mathrm{C}\right)$. This response was also observed by Mila and Yang (2008), in which time to initial germination occurred more rapidly at temperature fluctuations of $8^{\circ} \mathrm{C}$ and below, compared with $12^{\circ} \mathrm{C}$ and above. The smallest temperature fluctuations in the southwestern region of Western Australia typically occur at periods of reliable rainfall when grain crops are initiating flowering and pathogen infection conditions are optimal.
Cumulative and total germination can be linked to both diurnal temperature and temperature fluctuations at the collection sites of the sclerotia. For example, populations from Mingenew were collected in an area characterized by a shorter growing season driven by higher spring temperatures when compared with populations collected at Darkan and Beverley. The daily maximum temperature at Mingenew exceeds $20^{\circ} \mathrm{C}$ approximately $25 \%$ of the time during the winter growing season (June to August), with a diurnal daily fluctuation of greater than $15^{\circ} \mathrm{C}$ occurring at a similar frequency (http:// www.bom.gov.au/). In comparison, at Darkan the daily maximum temperature is never above $20^{\circ} \mathrm{C}$, and the daily diurnal temperature fluctuation is rarely $15^{\circ} \mathrm{C}$ or greater. Sclerotia from Darkan subsequently showed a poor germination response at $20 / 4^{\circ} \mathrm{C}$, because this temperature did not conform to climatic conditions at the site over the winter growing period. Similarly, crop management strategies are adopted in the different regions to coincide with the response of crop phenology to these local weather patterns. For example, sowing dates and variety selection for time required to maturity and flowering are all used to optimize plant growth over the growing season and to reduce the risk of flowering occurring during frost or heat events, thus maximizing grain yield (Lilley et al. 2017; Zhang et al. 2013). These management activities will continually exert selection pressure on pathogen populations to correspond with crop phenology and seasonal conditions, to ensure potential crop infection in most years.

Ecological adaptation to a new environment and continued success are enhanced by a mixed mating structure (Bennett 2001). This has been widely researched in weeds (Michael et al. 2006; Owen et al. 2011) and pasture legumes (Bennett 1999; Bennett and Galwey 2002) but less so in plant diseases caused by $S$. sclerotiorum. The pathogen was believed to have a clonal population structure (Clarkson et al. 2013; Kohli et al. 1995), but recent research has showed that outcrossing can also occur (Attanayake et al. 2014; Derbyshire et al. 2019; Malvárez et al. 2007). There is also some evidence of recombination through sexual reproduction in S. sclerotiorum populations, which may increase the genetic diversity and adaptability of the pathogen (Aldrich-Wolfe et al. 2015). It is therefore suggested that diversity in populations of $S$. sclerotiorum provides a similar measure of protection through ecological adaptation to different environments and the ability to respond to seasonal variation between years. The preliminary MCGs of sclerotia from each of the populations included

Table 2. Parameter estimates $( \pm$ SE) generated from nonlinear regression analysis (three-parameter log-logistic) of cumulative carpogenic germination of five Sclerotinia sclerotiorum populations under four germination temperatures. Parameter $d$ is the upper asymptotic value of $Y, b$ is the slope of the curve around $t_{50}$, and $t_{50}$ is the time to reach $50 \%$ sclerote germination.

\begin{tabular}{|c|c|c|c|c|c|c|c|}
\hline \multirow[b]{2}{*}{ Temperature $\left({ }^{\circ} \mathrm{C}\right)$} & \multirow[b]{2}{*}{ Population } & \multicolumn{2}{|c|}{$\bar{b}$} & \multicolumn{2}{|c|}{$d$} & \multicolumn{2}{|c|}{$t_{50}$} \\
\hline & & Estimate & SE & Estimate & SE & Estimate & SE \\
\hline \multirow[t]{5}{*}{$\overline{15 / 4}$} & Bentley & -11.75 & $(3.85)$ & 0.65 & $(0.04)$ & 78.95 & $(4.14)$ \\
\hline & Beverley & -9.22 & (2.37) & 0.78 & $(0.04)$ & 71.73 & (3.68) \\
\hline & Darkan & -7.51 & (1.93) & 0.61 & $(0.05)$ & 80.47 & $(5.61)$ \\
\hline & Mingenew C & -13.27 & $(5.61)$ & 0.52 & $(0.04)$ & 75.28 & $(4.66)$ \\
\hline & Mingenew L & -6.54 & (1.14) & 0.91 & $(0.04)$ & 82.83 & (4.09) \\
\hline \multirow[t]{5}{*}{$20 / 15$} & Bentley & -3.41 & $(0.91)$ & 1.10 & $(0.32)$ & 109.61 & $(25.82)$ \\
\hline & Beverley & -6.92 & (1.67) & 0.82 & $(0.04)$ & 60.78 & $(3.23)$ \\
\hline & Darkan & -3.60 & $(0.82)$ & 0.83 & $(0.15)$ & 97.64 & $(15.53)$ \\
\hline & Mingenew C & -4.52 & (1.10) & 0.69 & $(0.08)$ & 79.78 & $(8.84)$ \\
\hline & Mingenew L & -4.85 & $(0.96)$ & 0.92 & $(0.04)$ & 63.62 & (3.96) \\
\hline \multirow[t]{5}{*}{$20 / 4$} & Bentley & -5.58 & (1.42) & 0.74 & $(0.11)$ & 102.89 & $(10.77)$ \\
\hline & Beverley & -8.55 & $(2.30)$ & 0.68 & $(0.05)$ & 83.02 & $(5.03)$ \\
\hline & Darkan & -14.16 & $(9.12)$ & 0.18 & $(0.03)$ & 77.84 & (7.48) \\
\hline & Mingenew C & -9.00 & $(3.40)$ & 0.50 & $(0.06)$ & 85.20 & (6.96) \\
\hline & Mingenew L & -6.30 & (1.71) & 0.70 & $(0.11)$ & 105.13 & $(10.03)$ \\
\hline \multirow[t]{5}{*}{$30 / 15^{a}$} & Bentley & - & & - & & - & \\
\hline & Beverley & - & & - & & - & \\
\hline & Darkan & - & & - & & - & \\
\hline & Mingenew C & - & & - & & - & \\
\hline & Mingenew L & - & & - & & - & \\
\hline
\end{tabular}

a No germination was observed for $30 / 15^{\circ} \mathrm{C}$. 
in this study, based on the identified MCG groupings of isolates published by Denton-Giles et al. (2018), illustrate the diversity of isolates that are present between and within the populations in this study. In particular, a significant proportion of the isolates from each site (up to $40 \%$ ) were not able to be characterized, suggesting that there is considerably greater diversity than is published. A subsequent worldwide study by Derbyshire et al. (2019) further confirms the significant diversity in $S$. sclerotiorum. This diversity in field populations may also be influenced by other factors besides mating structure, such as sclerote contamination of crop grains. Research in this area is required but has been limited to date.

The present study focused on the temperatures required to initiate germination in the winter growing season of southwest Australia. Carpogenic germination of sclerotia of S. sclerotiorum is not only dependent on rainfall at the start of the growing season but also on temperature fluctuations experienced during the growing season. This results in different rates of germination between locations and subsequent time of spore release from apothecia. This study provides practical implications for agronomic decision-making and management, because conditions required for apothecia formation are a significant factor in determining the timing for fungicide application (Twengström et al. 1998). The inclusion of more populations and a wider range of diurnal germination temperatures would expand and strengthen our current understanding of the ecological structure of S. sclerotiorum and the potential spread of the pathogen.

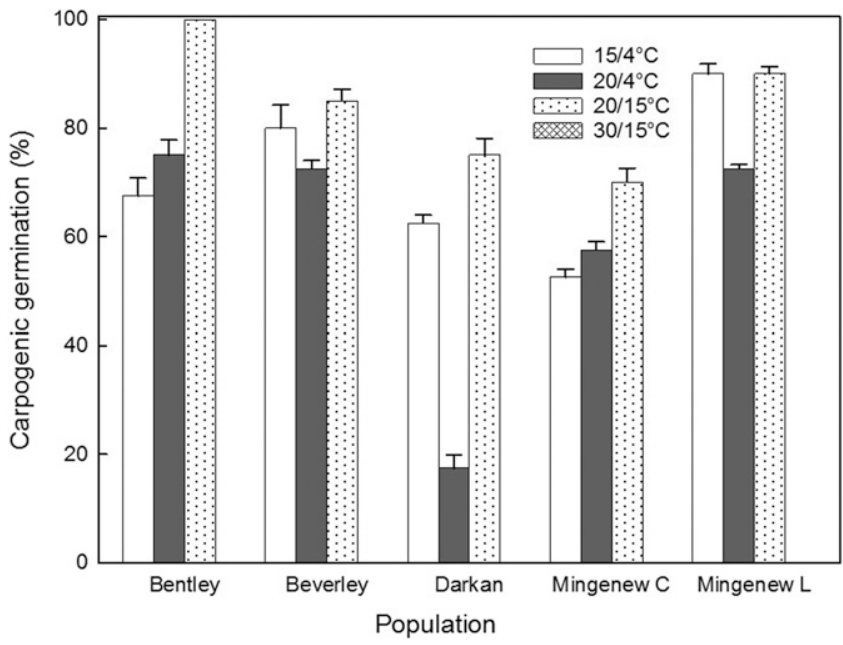

Fig. 4. Total carpogenic germination $( \pm \mathrm{SE})$ of five Sclerotinia sclerotiorum populations (Bentley, Beverley, Darkan, Mingenew C [canola], and Mingenew L [lupin]) incubated at four alternating temperatures $\left(15 / 4,20 / 15,20 / 4\right.$, and $30 / 15^{\circ} \mathrm{C}$; 12 -h/12-h light/dark) for 180 days.

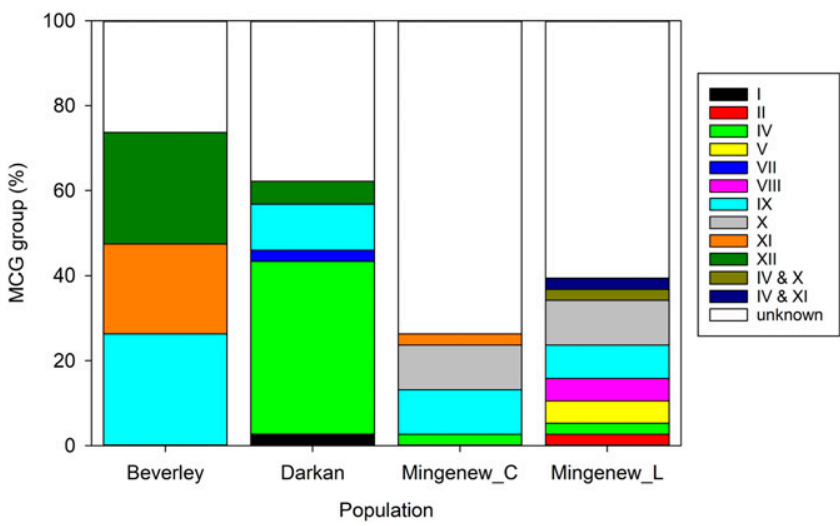

Fig. 5. Mycelial compatibility grouping (MCG) of four Sclerotinia sclerotiorum populations (Beverley, Darkan, Mingenew_C [canola], and Mingenew_L [lupin]), against 12 reference isolates developed by Denton-Giles et al. (2018).

\section{Acknowledgments}

The authors thank various farmers, Kyran Brooks (Landmark) and Matt Denton-Giles (Centre for Crop and Disease Management [CCDM]) for providing the sclerotia populations and Yuphin Khentry and Ashmita Lamichhane (CCDM) for laboratory assistance.

\section{Literature Cited}

Abawi, G. S., and Grogan, R. G. 1979. Epidemiology of disease caused by Sclerotinia species. Phytopathology 69:899-904.

Aldrich-Wolfe, L., Travers, S., and Nelson, B. D. 2015. Genetic variation of Sclerotinia sclerotiorum from multiple crops in the north central United States. PLoS One 10:e139188.

Attanayake, R. N., Carter, P. A., Jiang, D., del Río-Mendoza, L., and Chen, W. 2013. Sclerotinia sclerotiorum populations infecting canola from China and the United States are genetically and phenotypically distinct. Phytopathology 103:750-761.

Attanayake, R. N., Tennekoon, V., Johnson, D. A., Porter, L. D., del Río-Mendoza, L., Jiang, D., and Chen, W. 2014. Inferring outcrossing in the homothallic fungus Sclerotinia sclerotiorum using linkage disequilibrium decay. Heredity 113:353-363.

Bell, D. T. 1999. The process of germination in Australian species. Aust. J. Bot. 47: 475-517.

Bennett, S. J. 1999. Ecotypic variation between and within two populations of Trifolium tomentosum (woolly clover) from Syria and Western Australia: Its success as a colonising species. Aust. J. Agric. Res. 50:1443-1450.

Bennett, S. J. 2001. Pollen-ovule ratios as a method of estimating breeding system in Trifolium pasture species. In: 10th Australian Agronomy Conference Agronomy Society of Australia, Hobart, Australia.

Bennett, S. J., and Galwey, N. W. 2002. The use of spatial analysis to measure the effect of environmental heterogeneity on genetic variation in Trifolium species from Sardinia. J. Agric. Sci. 139:283-294.

Boland, G. J., and Hall, R. 1994. Index of plant hosts of Sclerotinia sclerotiorum Can. J. Plant Pathol. 16:93-108.

Bolton, M. D., Thomma, B., and Nelson, B. D. 2006. Sclerotinia sclerotiorum (Lib.) de Bary: Biology and molecular traits of a cosmopolitan pathogen. Mol. Plant Pathol. 7:1-16.

Brooks, K. D., Bennett, S. J., Hodgson, L. M., and Ashworth, M. B. 2018. Narrow windrow burning canola (Brassica napus L.) residue for Sclerotinia sclerotiorum (Lib.) de Bary sclerotia destruction. Pest Manag. Sci. 74 2594-2600.

Clarkson, J. P., Coventry, E., Kitchen, J., Carter, H. E., and Whipps, J. M. 2013. Population structure of Sclerotinia sclerotiorum in crop and wild hosts in the UK. Plant Pathol. 62:309-324.

Clarkson, J. P., Fawcett, L., Anthony, S. G., and Young, C. 2014. A model for Sclerotinia sclerotiorum infection and disease development in lettuce, based on the effects of temperature, relative humidity and ascospore density. PLoS One 9:e94049.

Clarkson, J. P., Phelps, K., Whipps, J. M., Young, C. S., Smith, J. A., and Watling, M. 2004. Forecasting Sclerotinia disease on lettuce: Toward developing a prediction model for carpogenic germination of sclerotia. Phytopathology 94 . 268-279.

Clarkson, J. P., Phelps, K., Whipps, J. M., Young, C. S., Smith, J. A., and Watling, M. 2007. Forecasting Sclerotinia disease on lettuce: A predictive model for carpogenic germination of Sclerotinia sclerotiorum sclerotia. Phytopathology 97:621-631.

Denton-Giles, M., Derbyshire, M. C., Khentry, Y., Buchwaldt, L., and Kamphuis, L. G. 2018. Partial stem resistance in Brassica napus to highly aggressive and genetically diverse Sclerotinia sclerotiorum isolates from Australia. Can. J. Plant Pathol. 40:551-561.

Derbyshire, M. C., and Denton-Giles, M. 2016. The control of Sclerotinia stem rot on oilseed rape (Brassica napus): Current practices and future opportunities. Plant Pathol. 65:859-877.

Derbyshire, M. C., Denton-Giles, M., Hane, J. K., Chang, S., MousaviDerazmahalleh, M., Raffaele, S., Buchwaldt, L., and Kamphuis, L. G. 2019. A whole genome scan of SNP data suggests a lack of abundant hard selective sweeps in the genome of the broad host range plant pathogenic fungus Sclerotinia sclerotiorum. PLoS One 14:e0214201.

Dillard, H. R., Ludwig, J. W., and Hunter, J. E. 1995. Conditioning sclerotia of Sclerotinia sclerotiorum for carpogenic germination. Plant Dis. 79:411-415.

Durman, S. B., Menéndez, A. B., and Godeas, A. M. 2003. Mycelial compatibility groups in Buenos Aires field populations of Sclerotinia sclerotiorum (Sclerotiniaceae). Aust. J. Bot. 51:421-427.

Foley, M., Doğramac1, M., West, M., and Underwood, W. 2016. Environmental factors for germination of Sclerotinia sclerotiorum sclerotia. J. Plant Pathol. Microbiol. 7:379.

Garg, H., Kohn, L. M., Andrew, M., Li, H., Sivasithamparam, K., and Barbetti, M. J. 2010b. Pathogenicity of morphologically different isolates of Sclerotinia sclerotiorum with Brassica napus and B. juncea genotypes. Eur. J. Plant Pathol. 126:305-315.

Garg, H., Sivasithamparam, K., and Barbetti, M. J. 2010a. Scarification and environmental factors that enhance carpogenic germination of sclerotia of Sclerotinia sclerotiorum. Plant Dis. 94:1041-1047. 
Huang, H. C., and Kozub, G. C. 1991. Temperature requirements for carpogenic germination of sclerotia of Sclerotinia sclerotiorum isolates of different geographic origin. Bot. Bull. Acad. Sin. 32:279-286.

Huang, H. C., and Kozub, G. C. 1993. Influence of inoculum production temperature on carpogenic germination of sclerotia of Sclerotinia sclerotiorum. Can. J. Microbiol. 39:548-550.

Kamal, M., Savocchia, S., Lindbeck, K., and Ash, G. 2016. Biology and biocontrol of Sclerotinia sclerotiorum (Lib.) de Bary in oilseed brassicas. Australas. Plant Pathol. 45:1-14.

Kohli, Y., Brunner, L. J., Yoell, H., Milgroom, M. G., Anderson, J. B., Morrall, R. A. A., and Kohn, L. M. 1995. Clonal dispersal and spatial mixing in populations of the plant pathogenic fungus, Sclerotinia sclerotiorum. Mol. Ecol. 4:69-77.

Leyronas, C., Bardin, M., Berthier, K., Duffaud, M., Troulet, C., Torres, M. Villeneuve, F., and Nicot, P. C. 2018. Assessing the phenotypic and genotypic diversity of Sclerotinia sclerotiorum in France. Eur. J. Plant Pathol. 152:933-944.

Li, Y. B., Yongli, Z., and Nian, L. B. 1994. Study on the dissemination distance of sunflower stem rot fungus. Plant Prot. 20:12-13.

Lilley, J., Flohr, B., Whish, J., and Kirkegaard, J. 2017. Optimal flowering periods for canola in eastern Australia. In: Doing More with Less. 18th Australian Society of Agronomy Conference G. J. O'Leary, R. D. Armstrong, and L. Hafner, eds. Australian Society of Agronomy, Ballarat, VIC Australia. http:// www.agronomyaustraliaproceedings.org/.

Liu, J., Meng, Q., Zhang, Y., Xiang, H., Li, Y., Shi, F., Ma, L., Liu, C., Liu, Y., Su, B., and $\mathrm{Li}$, Z. 2018. Mycelial compatibility group and genetic variation of sunflower Sclerotinia sclerotiorum in northeast China. Physiol. Mol. Plant Pathol. 102:185-192.

Malvárez, G., Carbone, I., Grunwald, N. J., Subbarao, K. V., Schafer, M., and Kohn, L. M. 2007. New populations of Sclerotinia sclerotiorum from lettuce in California and peas and lentils in Washington. Phytopathology 97: 470-483.

Michael, P., Steadman, K., and Plummer, J. 2006. Climatic regulation of seed dormancy and emergence of diverse Malva parviflora populations from a Mediterranean-type environment. Seed Sci. Res. 16:273-281.

Mila, A. L., and Yang, X. B. 2008. Effects of fluctuating soil temperature and water potential on sclerotia germination and apothecial production of Sclerotinia sclerotiorum. Plant Dis. 92:78-82.
Murray, G. M., and Brennan, J. P. 2012. The Current and Potential Costs from Diseases of Oilseed Crops in Australia. Grains Research and Development Corporation, Kingston, CBR, Australia

Owen, M., Michael, P., Renton, M., Steadman, K., and Powles, S. 2011. Towards large-scale prediction of Lolium rigidum emergence. I. Can climate be used to predict dormancy parameters? Weed Res. 51:123-132.

Phillips, A. J. L. 1986. Carpogenic germination of sclerotia of Sclerotinia sclerotiorum after periods of conditioning in soil. J. Phytopathol. 116:247-258.

Purdy, L. 1956. Factors affecting apothecial production by Sclerotinia sclerotiorum Phytopathology 46:409-410.

Qandah, I. S., and Del Rio Mendoza, L. E. 2012. Modelling inoculum dispersal and Sclerotinia stem rot gradients in canola fields. Can. J. Plant Pathol. 34:390-400.

R Core Team. 2018. R: A language and environment for statistical computing. R Foundation for Statistical Computing, Vienna, Austria. https://www.Rproject.org/.

Ritz, C., Baty, F., Streibig, J. C., and Gerhard, D. 2015. Dose-response analysis using R. PLoS One 10:e0146021.

Schafer, M. R., and Kohn, L. M. 2006. An optimized method for mycelial compatibility testing in Sclerotinia sclerotiorum. Mycologia 98:593-597.

Sexton, A. C., and Howlett, B. J. 2004. Microsatellite markers reveal genetic differentiation among populations of Sclerotinia sclerotiorum from Australian canola fields. Curr. Genet. 46:357-365.

Sexton, A. C., Whitten, A. R., and Howlett, B. J. 2006. Population structure of Sclerotinia sclerotiorum in an Australian canola field at flowering and steminfection stages of the disease cycle. Genome 49:1408-1415.

Sun, P., and Yang, X. B. 2000. Light, temperature, and moisture effects on apothecium production of Sclerotinia sclerotiorum. Plant Dis. 84:1287-1293.

Twengström, E. R. S., Svensson, C., and Yuen, J. 1998. Forecasting Sclerotinia stem rot in spring sown oilseed rape. Crop Prot. 17:405-411.

VSN International. 2019. Genstat for Windows, 18th Ed. VSN International, Hemel Hempstead, U.K. https://vsni.co.uk

Wu, B. M., and Subbarao, K. V. 2008. Effects of soil temperature, moisture, and burial depths on carpogenic germination of Sclerotinia sclerotiorum and $S$. minor. Phytopathology 98:1144-1152.

Zhang, H., Berger, J. D., and Milroy, S. P. 2013. Genotype $\times$ environment interaction studies highlight the role of phenology in specific adaptation of canola (Brassica napus) to contrasting Mediterranean climates. Field Crops Res. 144:77-88. 